\title{
INVESTIGATION IN STRUCTURE AND MECHANICAL PROPERTIES OF A356 ALLOY WITH MICRO 100 AGENT ADDITIONS
}

\author{
Iryna Hren, Natasa Naprstkova, Stefan Michna \\ J. E. Purkyne University in Usti nad Labem, Czech Republic \\ iryna.hren@ujep.cz,naprstkova@fvtm.ujep.cz, stefan.michna@ujep.cz
}

\begin{abstract}
In recent years, aluminium alloys are still important because of their low density and good technological properties, together with good mechanical and corrosion properties. Various processes such as rolling, extrusion and powder metallurgy are available for production of an aluminium alloy component, but foundry processes play an important role. When casting these alloys, we often encounter internal defects, such as shrinkage and bubbles, which are the main factors affecting the quality of the casting. The requirements for casting quality are constantly increasing, so the aim is to eliminate these defects to the smallest possible amount and size. For this reason, current foundries are forced to guarantee the highest possible quality of castings. Deposits in aluminium alloys are produced mainly in castings with unfavourable wall thickness or in places of heat knots, which cannot be cast, for example, due to unsuitable casting construction. The shrinkage has a negative impact on the mechanical properties and pressure-tightness of the castings produced. Probat Fluss Micro100 helps improve the quality of castings. To evaluate the porosity, experiments were performed using light microscopy and EDX analysis. To confirm these results, a static tensile experiment was performed to confirm an increase in the strength values of the castings of these alloys after the use of Micro 100. Based on the results of the analyses, the optimum amount of these agents having the greatest effect on the A356 alloy was determined.
\end{abstract}

Keywords: aluminium alloy, microstructure, Micro100.

\section{Introduction}

During crystallization, all aluminium alloys are transformed from the disordered state of the liquid metal to a solid crystallographically arranged solid phase. This change in the state is also accompanied by a volume change before and after crystallization, where there is a volume reduction in the solid state alloy. For example, solidification of $100 \%$ liquid metal from a casting temperature of $720{ }^{\circ} \mathrm{C}$ to its room temperature will decrease to $93 \%$ of the original volume. Insufficient risering results in a volume change in the material, which manifests itself as shrinkage in the casting. Shrinkage in aluminium alloy castings has a negative impact on the mechanical and fatigue properties of the material. The solution for elimination of shrinkage and gasification may be the controlled filling of the melt with hydrogen [1-4]. During cooling (on solidification), the solubility of hydrogen decreases due to decreasing between the atomic distances. When the supersaturated state is reached, gas is formed in the form of bubbles. When individual hydrogen atoms do not fit between aluminium atoms, they form their own bubbles.

The amount of nucleation and hydrogen gas affects the number and size of the bubbles. Few crystallization nuclei and a lot of hydrogen produce a small number of large bubbles in the structure. This situation occurs, when gassing tablets, which release hydrogen in the melt, are applied. As the number of crystallization nuclei increases and with the same amount of hydrogen in the resulting structure, there will be more bubbles of smaller size. This process eliminates the deficiency of liquid metal in the thermal node. Formation of shrinkage will replace porosity in the alloy, which is neither $\mathrm{X}$-ray nor visible after machining [5].

Micro 100 is used in casting of complex castings with varying wall thicknesses and large thermal nodes. These nodes cannot be cast and cause formation of shrinkage cavities in the casting, which affects the strength and permeability while applying pressure.

The product is applicable to all foundry aluminium alloys cast by gravity, low pressure and pressure casting, as well as to prevent formation of shrinkage and to promote formation of evenly distributed micropores throughout the casting volume. This preparation replaces the formation of shrinkage or large bubbles (or pores) and creates conditions for development of micropores. The size of the formed pores depends on the solidification rate of the metal in the casting part [6]. When dissolving in the melt, the master alloy is capable of releasing the heterogeneous nuclei bubbles micrometer size. 
In large-scale production, it is possible to process aluminium alloy for up to three hours without any re-addition of the preparation and germ renewal. During solidification, hydrogen molecules are deposited on the nuclei and bubbles form. Until the bubble grows to oversized size, hydrogen is depleted.

The amount of Probat Fluss Micro 100 should be controlled to obtain suitable porosity parameters. According to literature sources, the recommended amount is in the range of 0.05$0.4 \mathrm{wt}$ \% by melt. It also depends on the technical parameters of the casting. This product can significantly improve the quality of castings [7;8].

\section{Experiment}

For experimental purposes hypoeutectic silicon $\mathrm{AlSi} 7 \mathrm{Mg} 0.3$ was used with the input chemical composition shown in Table 1. Filling was performed using Micro 100 in the form of wire. A total of 2 melts were cast, the first without the addition of Micro 100 and the other using this shrinkagepreventing agent in an amount of $0.1 \mathrm{wt} . \%$. The individual melting, refining and filling operations were performed in a furnace at $720^{\circ} \mathrm{C}$. At each melt, the melt was treated with refining salt and swabs were removed from the impurities. The melt was cast by the gravity casting technology into a metal mould preheated to $280^{\circ} \mathrm{C}$.

Chemical composition of casting, wt. \%

Table 1

\begin{tabular}{|c|c|}
\hline $\mathbf{S i}$ & 7.01 \\
\hline $\mathbf{F e}$ & 0.2 \\
\hline $\mathbf{C u}$ & 0.05 \\
\hline $\mathbf{M n}$ & 0.1 \\
\hline $\mathbf{M g}$ & 0.4 \\
\hline $\mathbf{A l}$ & residual \\
\hline
\end{tabular}

\section{Structure microscopy}

Metallographic sections were prepared from castings of $\mathrm{AlSi} 7 \mathrm{Mg} 0.3$ alloy for evaluation of the microstructure. The microstructure of the prepared castings, after etching with nitric acid, was observed on an Olympus Lext OLS 3100 confocal laser microscope.

The first set of samples was cast without the addition of Micro 100. Figure 1 shows the starting microstructure of hypoeutectic unmodified silumin, consisting of $\alpha$-phase grains and a eutectic consisting of hexagonal platelets of eutectic silicon distributed in $\alpha$-solid solution. On metallographic pattern these plates appear as needles which have dark grey colour.

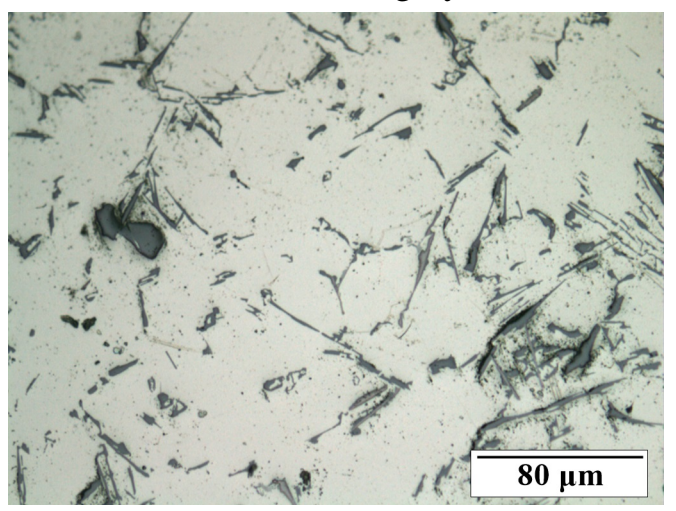

Fig. 1. Microstructure of AlSi7Mg0.3 alloy

Figure 2 reveals the typical morphology of the micro-space created by shrinkage and gas evolution in the solidification process. Larger pores seen by the eyes appeared in some areas of Sample 1. 

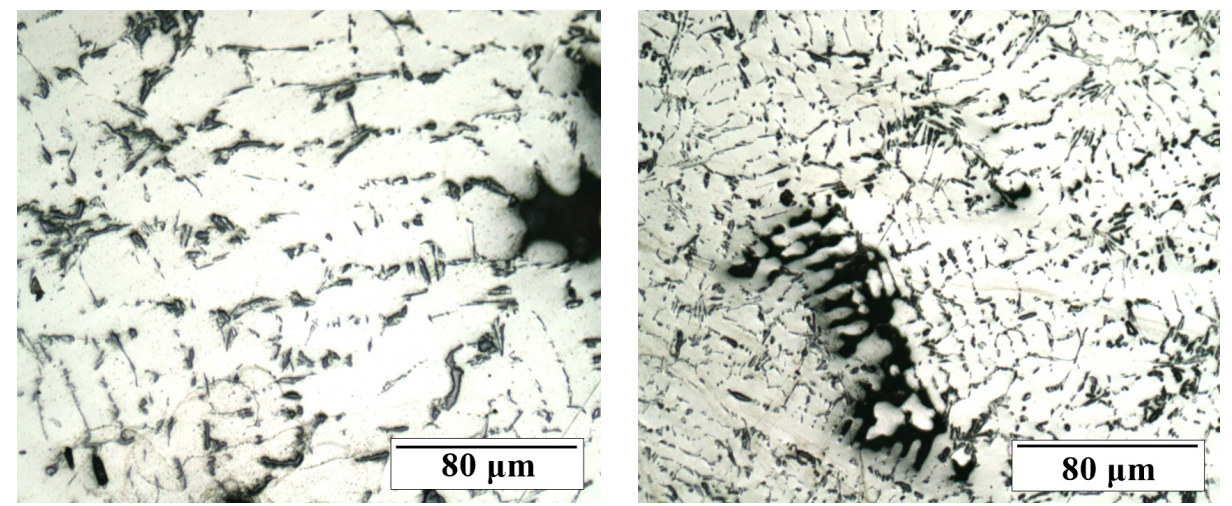

Fig. 2. Microstructure of AlSi7Mg0.3 alloy without using Micro 100

Ten pore size measurements were performed to assess microporosity for each sample. Porosity was measured in different areas of the cut using an Olympus LEXT OLS 3100 laser optical microscope and image analysis methods. The results of the measured porosity values as a percentage of the total image area of a sample without the use of Micro 100 are shown in Table 2.

Table 2

\section{Measurement of porosity of sample A1 cast from AlSi7Mg0.3 alloy, sample identification - 1}

\begin{tabular}{|c|c|}
\hline Measurement & Porosity, \% of image area \\
\hline 1 & 1.635 \\
\hline 2 & 2.014 \\
\hline 3 & 2.722 \\
\hline 4 & 2.535 \\
\hline 5 & 1.193 \\
\hline 6 & 1.251 \\
\hline 7 & 1.641 \\
\hline 8 & 2.041 \\
\hline 9 & 1.987 \\
\hline 10 & 2.312 \\
\hline Average & 1.933 \\
\hline
\end{tabular}

These samples were prepared from the most porous part of the AlSi7Mg0.3 casting alloy, reaching an average porosity of $1.933 \%$ of the image area.

The amount of Micro 100 contained in the second melt was $0.1 \mathrm{wt} . \%$. A considerable effect of this preparation on the resulting casting structure, which shows the occurrence of micro-porosity in smaller quantities, is shown in Figure 3.
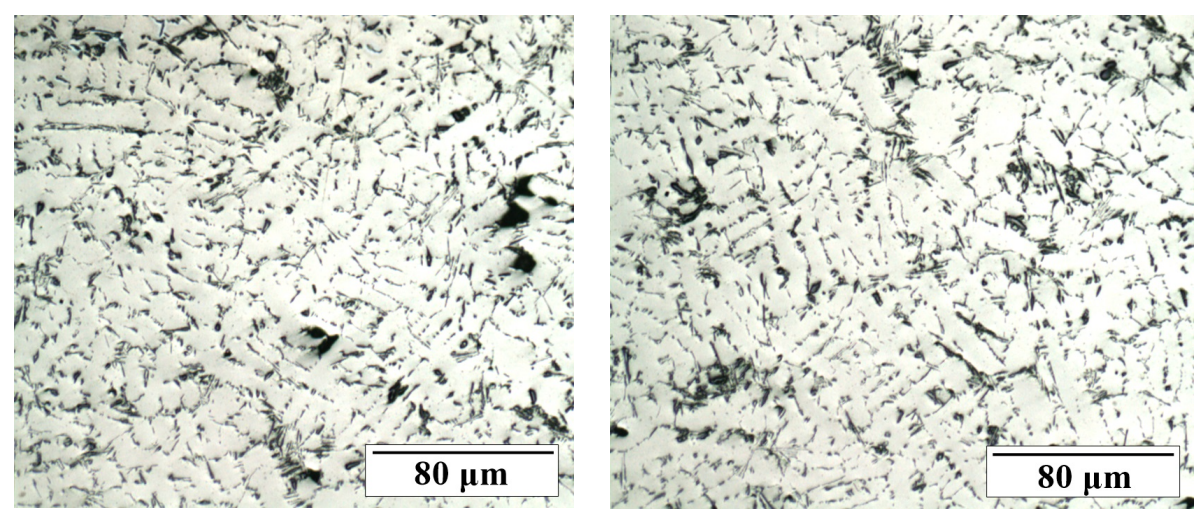

Fig. 3. Microstructure of AlSi7Mg0.3 alloy by using Micro 100 
Table 3 shows the measured porosity of sample 2, which was prepared from the most porous part of the AlSi7Mg0.3 alloy with the addition of Micro100.

Table 3

Measurement of porosity of sample cast from AlSi7Mg0.3 alloy with Micro 100 agent, sample identification -2

\begin{tabular}{|c|c|}
\hline Measurement & Porosity, \% of image area \\
\hline 1 & 1.025 \\
\hline 2 & 0.194 \\
\hline 3 & 1.022 \\
\hline 4 & 1.035 \\
\hline 5 & 0.952 \\
\hline 6 & 0.589 \\
\hline 7 & 1.035 \\
\hline 8 & 0.875 \\
\hline 9 & 0.984 \\
\hline 10 & 1.321 \\
\hline Average & 0.9032 \\
\hline
\end{tabular}

As it can be seen from the above analyses, the addition of Probat Fluss Micro100 to AlSi7Mg0.3 alloy significantly affects the morphology of the internal cavities in the castings, resulting in a reduction of the individual pores and also a decrease in the total porosity in the resulting casting.

\section{Static tensile test}

The static tensile test was performed according to EN ISO 6892-1. The tensile strength and ductility values of the alloys are shown in Figures 4 and 5.

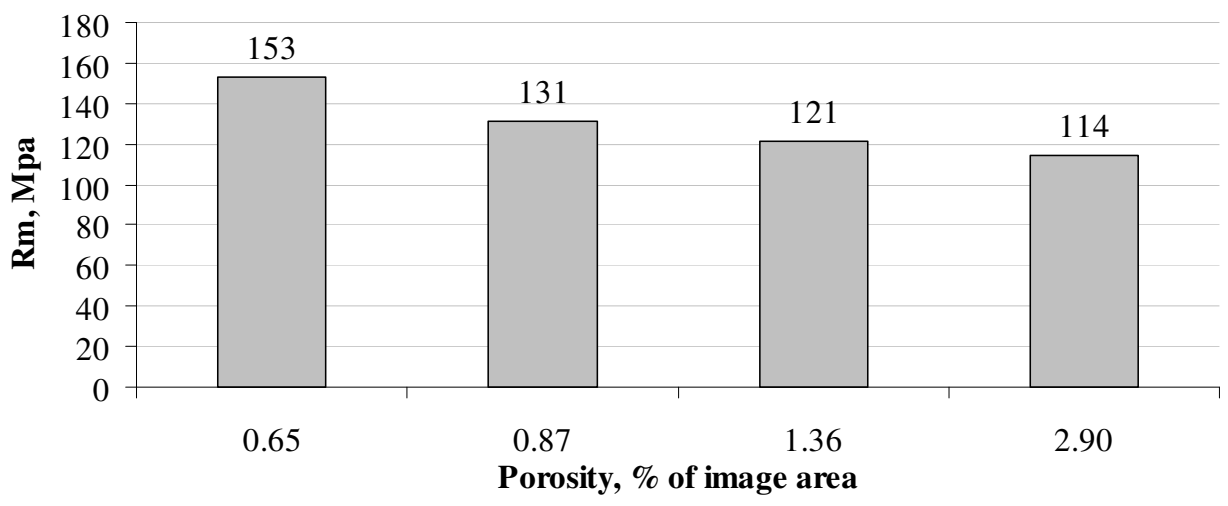

Fig. 4. Dependence of tensile strength on porosity, AlSi7Mg0.3 alloys

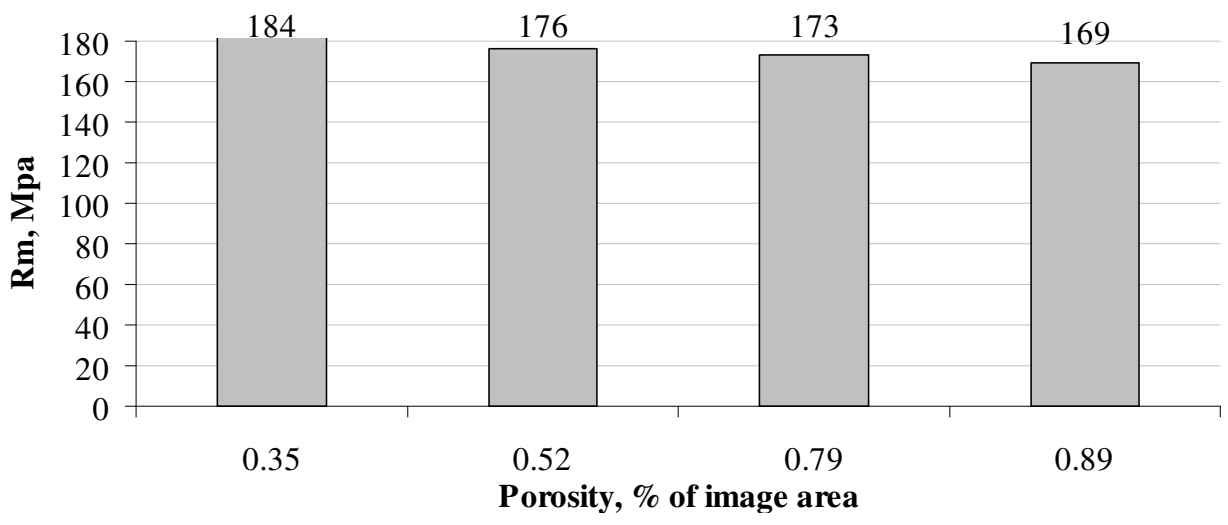

Fig. 5. Dependence of tensile strength on porosity, AlSi7Mg0.3 alloys by using Micro100 
An increase in the tensile strength was observed after addition of the Micro 100 reagent at a weight of $0.1 \mathrm{wt}$. \%. The ductility also reached higher values for the alloy with this addition, as shown in Figure 5.

\section{Fractographic analysis of cracks}

After the static tensile test, all samples were subjected to fracture analysis using a VEGA Tescan 3 electron microscope. Firgure 6 documents mainly interdendritic failure of the test rod. When examining the fracture surface in detail, it is possible to distinguish an area characterized by a ductile failure with exposed dendrites showing the occurrence of interdendritic porosity. On the fracture surface with local smooth decohesive separation of the material, the presence of a large oxide membrane (light area) not observed on a laser microscope can be observed.

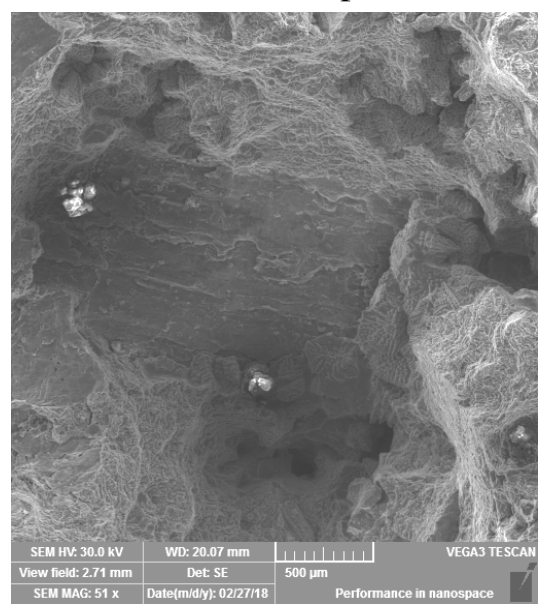

Fig. 6. Surface EDS analysis

The area analysed in Figure 7 shows predominantly interdendritic material failure. The microstructure shows areas with light spherical oxide particles and exposed dendrites. These particles increased local interdendritic porosity. The analysed surface at the quarry surface showed spherical rounding of the oxygen-containing particles. The presence of these oxides also caused failure of the test rod.

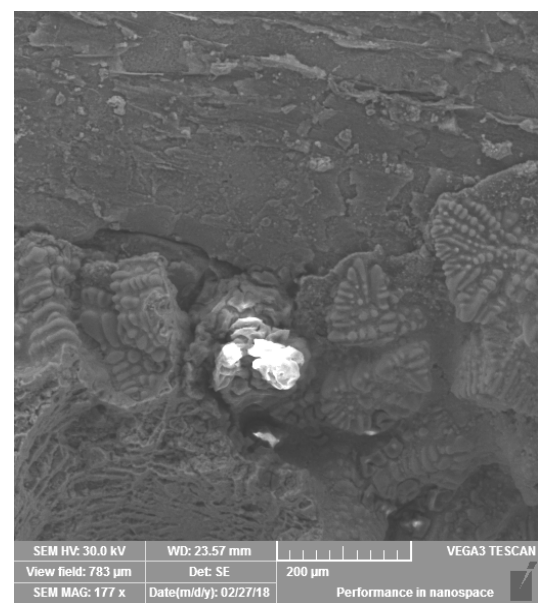

Fig. 7. SEM analysis - light spherical particles - oxides and exposed dendrites on the fracture surface

Figure 8 documents predominantly interdendritic failure of the test rod material. When looking at the fracture surface in detail, it is possible to distinguish areas characterized by ductile failure with pitting morphology. In the central part of the investigated area there are spherical particles containing oxygen and thus proving the presence of oxides on the surface of the quarry. 


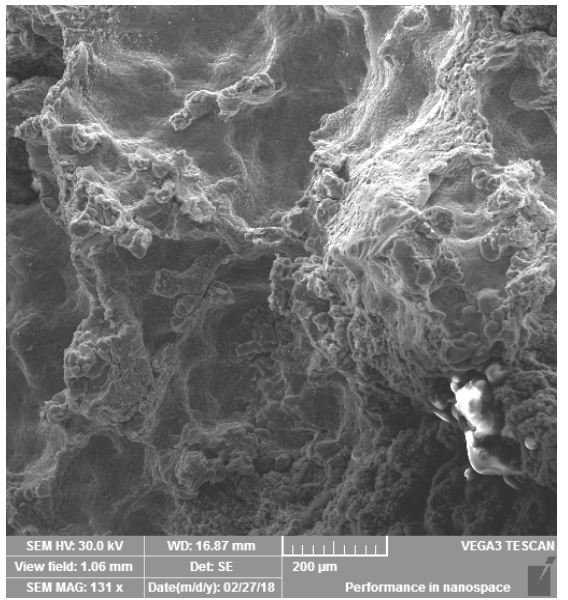

Fig. 8. SEM analysis - interdendritic failure, ductile failure with hole morphology

\section{Conclusions}

The aim of the experiment was to analyse the effect of Micro 100 on the final structure of the $\mathrm{AlSi} 7 \mathrm{Mg} 0.3$ alloy casting. From the results of the metallographic analysis performed of the samples with AlSi7Mg0.3 alloys, it can be stated that it is a hypoeutectic alloy formed by plates of eutectic silicon, which on metallographic pattern appears as grey needles and $\alpha$-phase dendrites. When using Micro 100, its effect on the resulting structure, which has a smaller pore size and achieves lower porosity percentage than the structure without using the preparation, is visible.

Fracture analysis of the fracture surface shows areas with light spherical particles (oxides) and exposed dendrites due to increased local interdendritic porosity. Spherical rounding of oxygencontaining oxide particles on the fracture surface was documented on the analysed area at the bottom of the casting, which initiated the failure of the test rod.

The static tensile test showed the relationship between the interdendritic porosity in the material structure and the mechanical properties of the material. An increase in the tensile strength of 30-40\% can be seen with a decrease in the porosity percentage from $1.9 \%$ to $0.9 \%$ of the total measured area.

\section{Acknowledgements}

This contribution was created within the support of the project SGS $48207152022-4801$ at UJEP.

\section{References}

[1] Collot J. Review of new process technologies in the aluminum die-casting industry. Materials and Manufacturing Processes, vol. 5, No. 16, 2011, pp. 595-617.

[2] Michna Š. Aluminium materials and technologies from A to Z. Prešov: Adin, 2007. 700 p.

[3] Bolibruchová D., Tillová E. Al-Si foundry alloys. Žilina: EDIS - ŽU, 2005. 180 p.

[4] Merlin M., Timelli G., Bonollo F., Garagnani G. L. Impact behaviour of A356 alloy for lowpressure die casting automotive wheels. Journal of materials processing technology, vol. 209, No. 2, 2009, pp. 1060-1073.

[5] Hren I., Svobodova J. Fractographic analysis of strontium-modified Al-Si alloys. Manufacturing Technology, vol. 18, No. 6, 2018, pp. 900-905.

[6] Ibrahim M. F., Samuel E., Samuel A. M., Al-Ahmari A. M. A., Samuel F. H. Metallurgical parameters controlling them icrostructure and hardness of $\mathrm{Al}-\mathrm{Si}-\mathrm{Cu}-\mathrm{Mg}$ base alloys. Materials \& Design, vol. 32, No. 4, 2011, pp. 2130-2142.

[7] Michna Š., Lukáč I. Practical fractography. J. E. Purkyně University in Ústí nad Labem, OPTYS, spol. s r. o., 2012. 237 p.

[8] Timelli G., Caliari D., Rakhmonov J. Influence of process parameters and Sraddition on the microstructure and casting defects of LPDC A356 alloy for engine blocks. Journal of materials science \& technology, vol. 32, No. 6, 2016, pp. 515-523. 